\title{
Family and Marriage Counseling and HIV/Aids Pandemic in Nigeria
}

\author{
Christopher Kalu Okwun, Saedah Siraj \\ University of Malaya, Faculty of Education
}

\begin{abstract}
HIV/AIDS infected couples can now have a higher quality of life despite the fact that the serodiscondents does not change their family planning practices and fertility desires. This is supported by the fact that with the success of retrovirus therapy, many of the infected now live healthier lives and pursuing a wider range of activities. Many HIV/AIDS infected women today can participate in having their babies, with a significant chance of living to see their children grow into adulthood without infection. Based on the foregoing, the authors carried out qualitative interview research to determine the child bearing desires of serogative couple. Study findings show that two thirds of the interviewed women have high desires to have babies despite having full knowledge of their health condition. The authors conclude that collaborative partnership between family planning and HIV/AIDS services and HIV counseling as part of the integrated system will provide early intervention services to provide relief of anxiety about reproduction in an HIV infected woman to reduce HIV transmission and marriage breakup.
\end{abstract}

\section{Introduction}

Marriage is a social institution that is designed among other things to ensure the happiness and fulfillment of men and women who contract into. Marriage according to Olusanya [26] is a sacred and permanent contract between a man and a woman who have consented to live a life of fidelity and caring for each other for the purpose of promoting their mutual growth and welfare throughout their lives. The institution is however, not without its problems, as Kehinde [19] puts it, marriage is like a house while new, it sparkles with fresh smell, with lots of surprises, romance and new discoveries about those involved which makes each day exciting to both partners but experiences have shown that not long after a family is established both partners become major sources of individual problems.

The fact that two people consent to live together as husband and wife implies different hopes and expectations, some of which might be fulfilled while others remain unfulfilled. Unfulfilled expectations and hope in marriage often give rise to maladjustments and unless the couples concerned face the reality of any given situation, conflicts might abound in such relationships. However, it is often inevitable that individuals involved in marriage relationship will experience conflict as Justin [38] puts it "Conflicts is seen as a situation whereby a husband and wife desire goals which may be perceived as attainable by one but not by both” (p.7) In such situations, the characteristic of the family reflects incompatibility, interactive struggle and interference. To buttress this, Gangle and Carine [28] postulated that conflict is associated with anger, criticism and struggles, adversity, tension, battle, fight, trouble, challenge, pressure and warfare. Hauck [15] opined that when there are differences in opinion, undefined roles and choices of goals, these are fertile grounds for conflicts. If such conflict is not resolved at the initial stage it may cause separation and divorce. Arising out of concern for those expressed fears, Cook [9] stated that couples need to learn how to negotiate marital conflicts because they arise in families at critical developmental periods. The dynamics of marriage institutions is a subject of continuing interest to the counselors. 


\section{Couples and HIV/AIDS}

In Africa and Nigeria in particular pregnancy is considered a means of redeeming a woman's relationship with her husband and of protecting her against the risk of rejection and abandonment and of maintaining recognized status as a wife and mother. In case of HIV/AIDS epidemic, it is critical that a new strategic plan for HIV discordant couples is given extensive counseling on the use of reproductive technologies such as donor sperm and insemination. It is common that women who have had history of an HIV infection are often left with guilt, fears and unresolved grief, which affects their psychology, motivation and readiness for sex. However, increasingly safe sexual behavior among HIVinfected individuals has become a priority for the Centre of Disease Control (CDC) of Nigeria whose goal is to reduce new HIV infection. An important component of this new strategic plan for HIV infected individuals is the incorporation of HIV prevention counseling into routine medical care of HIV-infected persons. Relationship-based risk reduction intervention encourages collaboration to address mutual needs. They also enable couples to gain a more realistic appraisal of their risk for HIV as a couple. The question here is should partner notification of HIV precipitate the breakup of relationships? However, it may cause notified individuals to abuse their partners emotionally or physically. In Nigeria, many churches insist on necessity of HIV screening before each wedding. Despite all these measures, the rate of HIV infection among couple continues to increase. The question is what should be done to maintain peaceful live in a situation where the man or woman has HIV. Specifically, the study raises the following questions: Would the couples exposed to HIV/AIDS show greater reduction in marital conflict than those not affected? And what would be the relative effectiveness of family Cognitive Restructuring to the spouse? These questions are the basis of this article and underscore the importance of counseling to facilitate informed decision-making on childbearing. .

\section{Statement of the problem}

Recent studies have shown that many infected HIV couples desire and expect to have children. This has important implications for the prevention of mother to child transmission of HIV. The Risk of HIV transmission among individuals is likely to increase more. Infected individuals choose to have children with their HIV-serogative partners. It is certainly necessary to support these individuals without sacrificing the health and well-being of their new born.

\section{Purpose of the study}

There is no national demographic survey for the purpose of examining the impact of HIV/AIDS on trends in reproductive behavior of infected Nigerians. This work will provide an insight into such trends in Nigeria.

\section{Research methodology and respondent}

This study was carried out in Aba, Abia state Nigeria with the purpose to improve the quality of life of married couples especially of HIV couples. It consists of providing family and marriage counseling services to married people using a variety of qualitative research approaches including Semistructured interviews and short questionnaires.

\section{Population and Sample}

The population of the study comprised 46 couples in a reproductive health counseling program in Aba, Abia State. They were selected for interviews by convenience sampling. Mean age of respondent is 32 years (range 24-40 years). The sample was derived only from those who came for counseling. The sampling technique employed was purposive sampling because specific situation was being addressed. All subjects first volunteered and were later selected using their responses in the semistructured interviews and short questionnaire. The sample was drawn from those who score 40 and below on the Marital Happiness Scale (MHS), 44-81 on the Irrational Value Sacle (IVC) and 74 or less on the Marital Communication Ratting (MCRC). 90\% were able to explain HIV/AIDS/STI infections, the mode of HIV/AIDS spread and preventive measures, $30 \%$ can use condom properly. $90 \%$ of the women want the children with/without HIV/AIDS infections, $50 \%$ of the men want to have children - that is to have large family, $76 \%$ had secondary school education and above.

The rising incidence of divorce, separation and HIV/AIDS has led to a social economic and reproductive health concerns that demands for counseling services. The results will help re-design on-going AIDS patient care and address the issue of reproductive health and new hope for people living with HIV/AIDS and childbirth was not real to many PLWAS and the non-infected but their opinions changed after being told that it is possible to have children even after infection. 


\section{Discussion}

Too many Africans and Nigerians in particular believe that a marriage which remains for a long time without a child has lost its meaning and thus, for them the marriage is not perfect without children. Since children are wanted to continue the lineage of family history. In most societies childless couples are not considered as truly married until the arrival of their first child, this is because in the traditional African society, a woman is truly accepted by her inlaws only after she has given birth to a child and especially if the child is male. Nwobi [23] asserts that inclination to damage another person's self image in the case of the husband and wife may be developed when a couple becomes aggrieved by a dent created on the image of the family by the bad behavior of one of them. For instance: Cognitive Restructuring involves instructing spouses to reduce their negative emotional reaction by getting them to interpret situations with greater accuracy. Ideally, it involves going married individuals avoid bad thinking instead to think objectively. The consensus in the study shows that HIV positive individuals does not have any negative or positive impact on fertility .Most women often learn of their status through antenatal unit after they are pregnant.

During counseling, couples are exposed to training and are being helped by the counselors to rethink their belief system and avoid the ones that have negative impact on their minds. Coleman and Tessy [10] speculated that HIV/AIDS might contribute significantly to the transformation of reproductive group of people in Africa. However, it is very hard to design empirical studies to validate Caldwell's views as it seems particularly in Nigeria with a prevalence of roughly 5 percent.

Results 1

The response to HIV/AIDS among the noninfected are assessed below by considering in turn, possible effects on fertility desires, sexual exposures, contraceptive behavior and post-partum behaviors.

An in-depth qualitative study to determine the extent to which awareness of HIV/AIDS has affected child-bearing and awareness created in the field of counseling.

Result 2

Survey data from rural Ngwa area provide more quantitative evidence, hence buttressing a conscious increase in fertility desires in response to the AIDS pandemic. One half of the respondents when asked directly expressed their desire to have fewer children because of AIDS. This is a self assessment from a cross-sectional observation of changing fertility desires.

\section{Effect on union formation and dissolutions}

One of the main issue on the AIDS pandemic on reproductive behavior in Nigeria is related to the possible effect on union formation and dissolutions..From the cross sectional surveys and data analysis of Nigeria the results indicate an increase in the rate of divorce, reflecting unwillingness to be unfaithful to their spouses. A trend towards sexual activity within marital unions to avoid and reduce HIV/AIDS could not be analyzed due to lack of data. For this Mcsweeney [21] holds that the net impact on fertility should be discussed separately.

\section{Implications for counseling}

The HIV counseling is a confidential dialogue between a client and a counselor aimed at enabling the client to cope with stress and take the necessary personal decisions related to HIV \AIDS. The counseling process includes evaluating the personal risk of HIV- transmission, and discussing how to prevent infection. It concentrates specifically on emotional and social issues related to possible or actual infection with HIV and to AIDS. With the consent of the client, counseling can be extended to spouses, sex partners and relatives (family-level counseling, based on shared confidentiality).

It is worthy of note that HIV counseling has as its objectives both prevention and care. A counselor is a trained professional in psychology to assist the client solve his/her problems. The counselor listens to the client, ask supportive questions, discuss options, encourage the client to make his own informed decision, giving practical information and suggesting follow-up.

Ideally, counseling is a process that involves many sessions and follow-up. Any location that offers peace and confidentiality is appropriate. It could be a clinic-based counseling that involves a formal session as is tenable in a hospital, health center or clinic by a trained professional, such as a doctor, social worker, nurse or a psychologist. Invariably, it could be Community-based that is counseling given in a nonformal environment. For instance, in a village or urban neighborhood by one community trained in counseling to another community or family member WHOIUNAIDS, [31].

\section{Pre-test counseling}

It is expedient to note that HIV counseling is often given a voluntary HIV test. Such counseling helps to 
prepare the client for the test, explains the implications of knowing that one is or is not infected with HIV, and facilitates discussion on ways to cope with knowing one's HIV status. It involves discussion of sexuality, relationships, possible sex and drugrelated risk behaviors, and how to prevent infection. It assists to correct misinformation. Pre-test counseling should be accessed to those who want it and for voluntary HIV test. The writers suggest that consent is always required before HIV test where the individual will be linked to the result. This will help to reduce fear while waiting the test result.

\section{Post-test counseling}

The post-test counseling helps the counselee to adjust based on the outcome of the result on HIV test. The counselor prepares the mind of the client for the result, give the result and provides the client with information required or make referral where and when necessary. If the test result is positive, the counselor should tell the client clearly, and as gently and humbly as possible, providing emotional support and discussing with the client how best to cope. Ongoing counseling will help clients accept their HIV status, and take a positive attitude to their lives. Through ongoing counseling, the infected person may choose to confide in a trusted member of the family hence enabling the family to start practicing family-level counseling.

However, counseling is still accountable though it provided a negative result since it is a common in Asia especially Malaysia to stigmatize patient with HIV. While the client is likely to feel relief, the counseling should emphasize on some points as follows the first, the need to consider returning to repeat test after 3-6 months. The second, counselors need to involve and discuss HIV preventions; and the third provide encouragement to help the client to adopt and sustain any types of safer practices among others.

\section{Conclusion}

Fertility desires are driven by some social and economic considerations that are surprisingly robust in encountering AIDS pandemic.

It is widely known that economic costs of how HIV children are being maintained is enormous that is not enough valid reason of curtailing reproduction in our society. Some educated couples reason that many children and poverty increases the likelihood of acquiring AIDS, hence they see the argument about HIV/AIDS as a strategy for restricting fertility. However, this is self assessment from a cross sectional survey.

With the exception of studies by Orubuloye, Caldwell and Calwell [24] there are few investigations qualitative and quantitative of the extent to which awareness of HIV/AIDS has changed childbearing aspirations. There is a need for further research on the ways in which consciousness of AIDS pandemic is or is not transforming reproductive strategies.

All hands should be on deck not only to allay the fear that is confronting the HIV patient but also do away with the pandemic. According to the Joint United Nations Program on (HIV \AIDS) in 2007, between 30.6 and 36.1 million people are believed to live with HIV, and it killed an estimated 2.1 million people that year, including 330,000 children. There were 2.5 million infections. Sub-Saharan Africa remains by far the worst-affected region, with an estimated 21.6 to 27.4 million people currently living with HIV. South-East Asia is second-worst affected with $15 \%$ of the totality accounts for the deaths of 500,000 children in this region. South Africa has the largest number of HIV patients in the world followed by Nigeria. India has an estimated 2.5 million infections ( $0.23 \%$ of population), making India the country with the third largest population of HIV patients. In the 35 African nations with the highest prevalence, average life expectancy is 48.3years less than it would be without the disease. However, with the introduction of anti-retrovirus drugs married couples can still live longer, enjoy their marriage and procreate children who will not be affected with the pandemic.

\section{References}

[1] American Psychological Association. (1987). General guidelines for providers of psychological services. Washington, DC: Author.

[2] Allison, K.W., Crawford, I., Echemendia, R., Robinson, L., \& Knepp, D. (1994). Human diversity and professional competence: Training in clinical and counseling psychology revisited. American Psychologist, 49, 792-796.

[3] American Psychological Association. (1992). Ethical principles of psychologists and code of conduct. American Psychologist, 48, 1597-1611.

[4] American Psychological Association. (1999). Professional practice guidelines for psychotherapy with lesbian, gay and bisexual clients. Joint Task Force on Professional Practice Guidelines for Psychotherapy with Lesbian, Gay and Bisexual Clients. Unpublished manuscript.

[5] Allen S., Serufilira A., Bogaerts J. et al (1992). Confidential HIV testing and condom promotion in Africa: 
impact on HIV and gonorrhoea rates. Journal of American Medical Association, 268(23), 3338-3343.

[6] Aurthur P., (2000). Survey of African marriage and family life (ed). London: Oxford University Press.

[7] Adeyi, et al. (2006). Aids in Nigeria: A nation on the threshold, The epidemiology of HIV \AIDS in Nigeria: Harvard Center of Population and Development Studies.

[8] Bronstein, P.A. \& Quina, K. (Eds.). (1988). Teaching a psychology of people. Washington, DC: American Psychological Association.

[9] Cook, D.A. (1994). Racial identity in supervision. Counselor Education and Supervision, 34, 132-141.

[10] Coleman and Tessy (1984) 'Family disruption,social indices and behaviour problem'.Journal of Marriage and Family, 37,497-502.

[11] Day, N.A. (1990). Training providers to serve culturally different AIDS patients. AIDS: Clinical perspective [Special issue]. Family and Community Health, 13, 46-53.

[12] Fincham T.O., (2004). New York: American publication Marital conflict X-ray.

[13] Gandle O. K. \& Carine S.L. (1992). Communication and conflict management (ed). New York: Breadman Press.

[14] Hardy, K.V. (1990). The theoretical myth of sameness: A critical issue in family therapy training and treatment. In G.W. Saba, B.M. Karrer, \& K.V. Hardy (Eds.), Minorities and family therapy (pp. 17-33). New York: Haworth.

[15] Hauck, P. (1983). 'Marriage and family in a changing Society'. London Free Press collier Macmillan Publishing Company.Inc.

[16] Hoshman, L.S.T. (1989). Alternate research paradigms: A review and teaching proposal. The Counseling Psychologist, 17, 3-79.

[17] Herring, R. D., (1999). Counseling with Native American Indians and Alaska Natives: Strategies for helping professionals. Thousand Oaks, CA: Sage.

[18] Justin J.C. (2004) Conflict Resolution Skills Training \& Rational Emotive Therapy on the Improvement of Marital Adjustment of Married Workers. Unpublished PhD Thesis Abia State University.

[19] Kehinde E. (2002). The relative effectiveness of conflict resolution skills training on marital adjustment of some selected couples in the counsellor, 19(1), 1-11.

[20] LaFromboise, T.D., \& Foster, S.L. (1992). Crosscultural training: Scientist-practitioner model and methods. Counseling Psychologist, 20, 472-489.
[21] Mcsweeney, L., (1992), AIDSyour

Responsibility,Ibadan:The Ambassador Press.

[22] Myers, H.F., Wohlford, P., Guzman, L.P. \& Echemendia, R.J. (Eds.). (1991). Ethnic minority perspectives on clinical training and services in psychology. Washington, DC: American Psychological Association.

[23] Nwobi, P.C., (1997). 'Marriage and Family Counselling’ Jos Fab Anieh Ltd, 12,52-61.

[24] Orubuloye, I.O.,Calwell,J.C.\&Calwell,P.(1991).Sexual Networking in Ekiti District of Nigeria of Nigeria.Studies in Family Planning,22(2),61-73.

[25] Okwun, K.C. (2005). Effects of cognitive restructuring and communication skills training on conflict resolution among Nigerian couples, Unpublished $\mathrm{PhD}$. Thesis Abia State University.

[26] Olusanya, P.O. (1970). A note on some factors affecting the stability of marriage among the Yoruba of Western Nigeria. Journal of Marriage and Family. February 150-155.

[27] Okojie, C.E. (1990). Nigerian women in public sector, Journal of Management in Nigeria, 26 (6), 47-53.

[28]Peterson, R.L., Peterson, D.R., Abrams, J.C., \& Stricker, G. (in press). Standards for education in professional psychology: The integrated resolutions of the conferences of the National Council of Schools and Programs of Professional Psychology. In Standards for education in professional psychology. Washington, DC: American Psychological Association and National Council of Schools of Professional Psychology.

[29] Richards, H., \& Clements, C. (1993). Critique of APA Accreditation Criterion II. Cultural and individual differences. Professional Psychology: Research and Practice, 24, 123-126.

[30] UNAIDS. (1997) UNAIDS policy on HIV testing and counselling: Geneva.

[31] WHO\UNAIDS. (2007). Key to counselling. AIDS Action Newsletter, 24. London: University Press.

[32] Valuing diversity in Faculty: A guide. (1997). Commission on Ethnic Minority Recruitment, Retention, and Training in Psychology. Washington, DC: American Psychological Association.

[33] Westwood, M.J., \& Lawrance, S. (1990). Uprooted: Towards a counsellor understanding of the refugee experience. International Journal of Advancement Counseling, 13, 145-153. 